\title{
Research on energy loss of MPPT and its improvement
}

\author{
XuYang Zhang ${ }^{1, a}$, HuaGuang Zhang ${ }^{1, b}$, PengQiao Zhang ${ }^{1, c}$, YangYang \\ Wang $^{1, d}$, BingQing $\mathrm{Li}^{2, \mathrm{e}}$ and Xu Sun ${ }^{3, \mathrm{f}}$ \\ ${ }^{1}$ School of Information Science and Engineering, Northeastern University, Shenyang 110819, \\ China; \\ ${ }^{2}$ Construction management center of State Grid Liaoning Electric Power Supply CO., LTD., Liaoning \\ Province, 110000, China; \\ ${ }^{3}$ State Grid Chaoyang Electric Power Supply Company, Liaoning Province, 122000, China. \\ azxy1083604729@126.com, 'zhanghuaguang@mail.neu.edu.cn, ${ }^{\mathrm{c}} z$ pq19911218@126.com, ${ }^{\mathrm{d}} 1323$ \\ 4043671@163.com, 'Li13889224204@163.com, 'sunxu_neu@163.com
}

Keywords: Photovoltaic, Maximum Power Point Tracking (MPPT), Misjudgment, Oscillations, Energy loss.

\begin{abstract}
Output power of photovoltaic cells is greatly related with light intensity and temperature, in order to achieve maximum output power, it is necessary to implement maximum power point tracking (MPPT).This paper analyses misjudgments, oscillations and energy loss during MPPT by fractional Open-Circuit Voltage method, perturbation and observation method, incremental conductance method. An improved perturbation and observation method is proposed to reduce oscillations and energy loss and improve the speed and accuracy of tracking.
\end{abstract}

\section{Introduction}

With the advent of industrial economy and the energy crisis, clean, non-polluting and renewable energy has become a global focus. Today in the pursuit of low-carbon economy, solar energy as a new energy source, has globally transformed from "auxiliary energy" to "alternative energy". Solar photovoltaic power generation is an important form of solar energy utilization. Compared with fossil energy, nuclear and wind, solar energy has a characteristic of a wide distribution, no noise, pollution-free, inexhaustible. In PV systems, conversion efficiency of photovoltaic cells associates not only with characteristics of cells, but also environment, such as irradiance, temperature and load factors. In different external conditions, photovoltaic cells run in a different and unique maximum power point (MPP). Therefore, for PV systems, seeking the optimal working condition in order to maximize the conversion of light energy into electrical energy, is an effective way to improve the efficiency of photovoltaic.

Current MPPT methods mostly are: fractional Open-Circuit Voltage method (CVT method), perturbation and observation method (P\&O method) and incremental conductance method (INC method) [1]. CVT method, is high stable, easy to implement, but the impact on pen circuit voltage by junction temperature is not taken into account of , which will causes energy loss and lead to not accurately tracking the maximum power point, only an approximate tracking. P\&O method is one of the most common method, but its slow tracking, oscillations near MPP and misjudgments issues that may occur when rapidly environment changes, which can cause energy loss. To some degree, INC method can solve the above problem, but when the light intensity varies rapidly, miscalculation and oscillation still occur. In response to these issues, this paper carries out a detailed analysis of the energy loss in the above three methods during MPPT, and an improved P\&O method to reduce oscillations and energy loss and improve the speed and accuracy of tracking is proposed.

Energy loss analysis of fractional Open-Circuit Voltage method.

The principle of the fractional Open-Circuit Voltage method is the near linear relationship between $V_{m}$ and $V_{o c}$ of the PV array, $V_{m} \approx \mathrm{K}_{1} * \mathrm{~V}_{\text {oc }}$, $\mathrm{k}_{1}$ is a constant of proportionality. Since $\mathrm{K}_{1}$ is dependent 
on the characteristic of the PV array, it usually has to be computed beforehand by empirically determining $V_{m}$ and $V_{o c}$ for the specific PV array at different irradiance and temperature levels. The factor $K_{1}$ has been reported to be between 0.71 and 0.8 . Since $K_{1}$ is a constant, energy loss is caused.

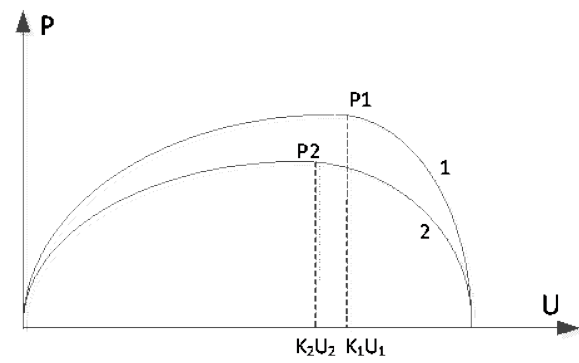

Fig. 1 Analysis of CVT's energy loss

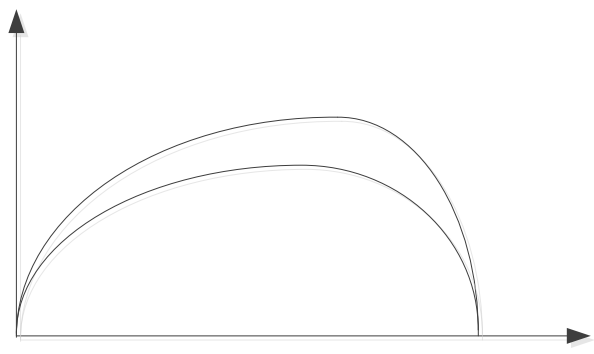

Fig. 2 Misjudgment analysis of P\&O method

When the temperature and light intensity are certain, hypothetically, system runs in the curve 1, choose the right $\mathrm{K}_{1}=0.78$, in an ideal case that the external light intensity and temperature changes little, the system happens to work at MPP. However, due to constant changes in light intensity and temperature, the probability that $\mathrm{K}_{1}=0.78$ just work at MPP is very small, but close to the MPP, the actual voltage is. Due to the voltage difference is very small, current can be considered constant, energy loss can be calculated from the equation:

$$
\mathrm{P}_{\text {loss }}=\left(0.78 * V_{\text {oc }}-0.77 * V_{\text {oc }}\right) /\left(0.77 * V_{\text {oc }}\right)=1.30 \%
$$

If the temperature and light intensity vary rapidly, system P-U curve will change from 1 to 2 . The $\mathrm{K}_{1}$ selected before was 0.78 ,howev $V_{m}=0.77^{*} \mathrm{~V}_{\text {oc }}$ er, the $\mathrm{K}_{1}$ in the curve 2 is actualy 0.72 , $V_{m}=0.72 * \mathrm{~V}_{\text {oc }}$, the voltage difference is large. According to the PV characteristic U-I curve, current will be also different. Hpothetically, the working current $I_{k 1}$ in $\mathrm{U}=0.78 * \mathrm{Uoc} 2$ is as 0.85 times as $I_{\mathrm{m}}$ in the curve $2, \mathrm{I}_{\mathrm{k} 1}=0.85 * \mathrm{I}_{\mathrm{m}}$.Energy loss can be calculated from the equation:

$$
\mathrm{P}_{\text {loss }}=\left(0.72 \mathrm{U}_{\text {oc } 2} * \mathrm{I}_{\mathrm{m}}-0.78 \mathrm{U}_{\text {oc } 2} * 0.85 \mathrm{I}_{\mathrm{m}}\right) /\left(0.72 \mathrm{Uoc} * \mathrm{I}_{\mathrm{m}}\right)=7.91 \%
$$

\section{Energy loss analysis of P\&O method.}

When implement P\&O method for MPPT, near MPP and misjudgment issues may occur when rapidly environment changes. Analyses of causes and energy loss are done in the two cases respectively, as following.

\section{(1) Misjudgment of $P \& O$ method}

Although P\&O method is simple and easy to control, but it also has some disadvantages: in steady-state case, output voltage oscillate near at MPP, and when the light intensity varies rapidly , misjudgment may occur. In the steady-state condition, the system quickly converge to MPP, therefore, analysis near MPP is done. As shown in Fig.2 are the P-U characteristic curves in different light intensities. If the system is initially running at P11 in the curve 1, based on P\&O method, the system will run to the $\mathrm{P}_{12}$, if the light intensity does not change. But after that, if light intensity mutations from 1 to 2, the $P V$ system will falsely run from $P_{22}$ to $P_{21}$, since $P_{11}>P_{22}$, in this way, the system will have a miscarriage and change disturbance direction, the PV system is actually supposed to run from $\mathrm{P}_{22}$ to $\mathrm{P}_{23}$,thongh . If the light intensity is still declining, working point will deviate from MPP, resulting in greater power losses.

Energy loss can be calculated from the equation when misjudgment does not occur:

$\mathrm{P}_{\text {loss } 1}=\mathrm{P}_{\mathrm{m} 2}-\mathrm{P}_{23}+\mathrm{P}_{\mathrm{m} 2}-\mathrm{P}_{22}+\mathrm{P}_{\mathrm{m} 1}-\mathrm{P}_{11}$

Energy loss can be calculated from the equation when misjudgment occurs:

$\mathrm{P}_{\text {loss } 2}=\mathrm{P}_{\mathrm{m} 2}-\mathrm{P}_{21}+\mathrm{P}_{\mathrm{m} 2}-\mathrm{P}_{22}+\mathrm{P}_{\mathrm{m} 1}-\mathrm{P}_{11}$

Energy loss caused by misjudgment can be calculated from the equation:

$$
\Delta \mathrm{P}_{\text {loss }}=\mathrm{P}_{\text {loss } 1}-\mathrm{P}_{\text {loss } 2}=\mathrm{P}_{23}-\mathrm{P}_{21}
$$

\section{(2) Oscillations of $\mathbf{P} \& O$ method}

According to P\&O method principle: even if running status is close to the MPP, there would still be oscillations near the MPP, some power loss is inevitable. There are two cases, one is showed in Fig. 
3(a),another in Fig.3(b). In Fig. 4(a), if the system is currently working at $U_{2}$ and step $\Delta u$ is greater than 0 , according to $\mathrm{P} \& \mathrm{O}$ method, the output voltage will
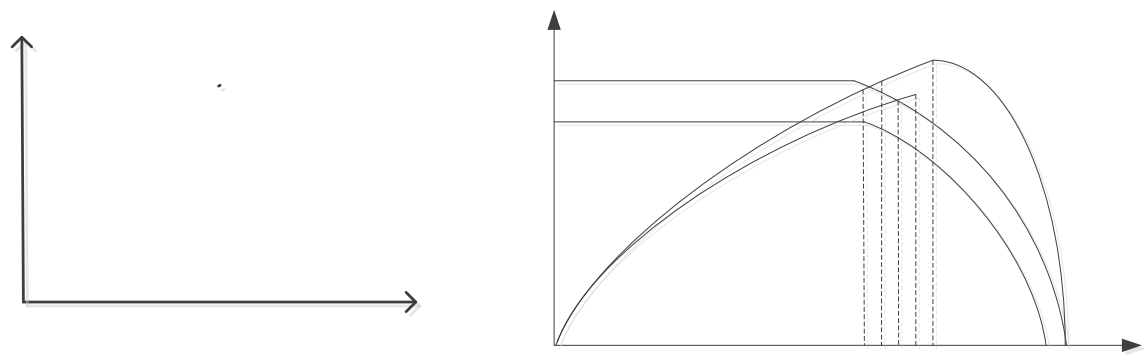

Fig. 3 Oscillations analysis of P\&O method

Fig. 4 Misjudgments analysis of INC method

be increased to $\mathrm{U}_{3}$, namely $\mathrm{U}_{3}=\mathrm{U}_{2}+\Delta \mu$. After adjusting ,system is working at $\mathrm{U}_{3}$. If $\mathrm{P}_{3}<\mathrm{P}_{2}$, based on $\mathrm{P} \& \mathrm{O}$ method, voltage will come back to $\mathrm{U}_{2}$. since $\mathrm{P}_{2}>\mathrm{P}_{3}$, voltage will continue to decrease to $\mathrm{U} 1$. Such a system will oscillate back and forth among $U_{1}, U_{2}, U_{3}$, until the outside world changes. If $\mathrm{P}_{3}>\mathrm{P}_{2}$, it is a similar discussion, $\mathrm{P}_{1}$ will be located in the right side of $\mathrm{P}_{3}$. Another case is showed in Fig.3(b), the system will oscillate back and forth among $\mathrm{U}_{1}, \mathrm{U}_{\mathrm{m}}, \mathrm{U}_{2}$.

Case1: Energy loss can be calculated from the equation:

$\mathrm{P}_{\text {loss }}=\mathrm{P}_{\mathrm{m}}-\mathrm{P}_{1}+\mathrm{P}_{\mathrm{m}}-\mathrm{P}_{2}+\mathrm{P}_{\mathrm{m}}-\mathrm{P}_{3}$

Case2: Energy loss can be calculated from the equation:

$\mathrm{P}_{\text {loss }}=\mathrm{P}_{\mathrm{m}}-\mathrm{P}_{1}+\mathrm{P}_{\mathrm{m}}-\mathrm{P}_{2}$

\section{Energy loss analysis of the INC method.}

In the INC method, working point of the system is determined on the left or right of the MPP by comparing $\mathrm{dI} / \mathrm{dU}$ and $-\mathrm{I} / \mathrm{U}$, and then decide to increase or decrease the voltage value. In actual implementation, $\mathrm{dI} / \mathrm{dU}$ is replaced by discrete $\Delta \mathrm{I} / \Delta \mathrm{U}$, which causes oscillation during MPPT. As the environment changes, as with $\mathrm{P} \& \mathrm{O}$ method, misjudgment may also occur.

\section{(1) Misjudgment of the INC method}

As showed in Fig. 4, curve11,21 are I-U characteristic curves; curve12,22 are P-U characteristic curves. Suppose the light intensity is $A$ in the $\mathrm{P}-\mathrm{U}$ curve 12 and working point is $\left(\mathrm{U}_{1}, \mathrm{P}_{11}\right)$, based on MPPT method, voltage value will increase. When light intensity varies to $\mathrm{B}$, the $\mathrm{P}-\mathrm{U}$ curve change to curve 22, working point is $\left(\mathrm{U}_{2}, \mathrm{P}_{22}\right)$. According to INC method, judging condition of disturbance is: $\left(\mathrm{I}_{21}-\mathrm{I}_{11}\right) /-\left(\mathrm{U}_{2}-\mathrm{U}_{1}\right)<\left(-\mathrm{I}_{21} / \mathrm{U}_{2}\right)$

Therefore, working point is identified on the right of MPP and voltage value will decrease back to $\left(\mathrm{U}_{1}, \mathrm{P}_{21}\right)$, however, working point is actually on the left of MPP. This is a misjudgment. If light intensity varies little, Equation (8) will be $\left(I_{21}-I_{11}\right) /-\left(U_{2}-U_{1}\right)>\left(-I_{21} / U_{2}\right)$, which would not lead to misjudgment.

Energy loss can be calculated from the equation when misjudgment does not occur:

$\mathrm{P}_{\text {loss } 1}=\mathrm{P}_{\mathrm{m} 2}-\mathrm{P}_{23}+\mathrm{P}_{\mathrm{m} 2}-\mathrm{P}_{22}+\mathrm{P}_{\mathrm{m} 1}-\mathrm{P}_{11}$

Energy loss can be calculated from the equation when misjudgment occurs:

$\mathrm{P}_{\text {loss } 2}=\mathrm{P}_{\mathrm{m} 2}-\mathrm{P}_{21}+\mathrm{P}_{\mathrm{m} 2}-\mathrm{P}_{22}+\mathrm{P}_{\mathrm{m} 1}-\mathrm{P}_{11}$

Energy loss caused by misjudgment can be calculated from the equation:

$\Delta \mathrm{P}_{\text {loss }}=\mathrm{P}_{\text {loss } 1}-\mathrm{P}_{\text {loss } 2}=\mathrm{P}_{23}-\mathrm{P}_{21}$ 


\section{(2) Oscillations of INC method}

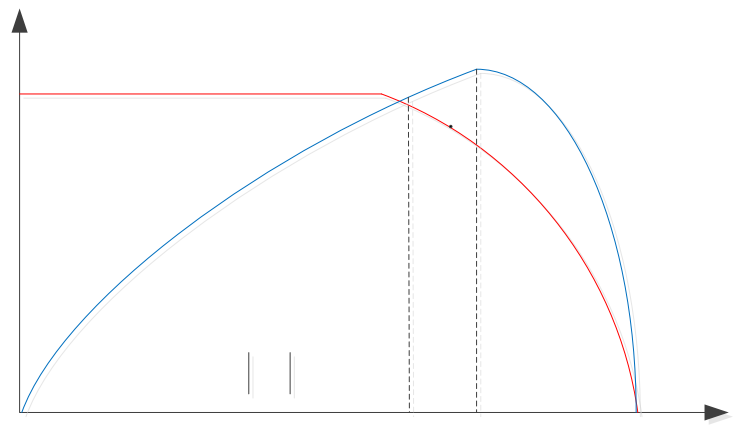

Fig. 5 Oscillations analysis of INC method

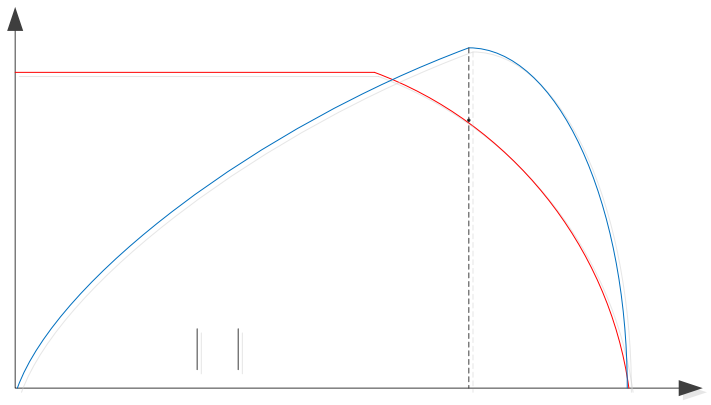

Fig. 6 Oscillations analysis when $U_{3}=U_{m}$

As can be seen from the Fig.5,when external conditions do not change, $\triangle \mathrm{I} / \triangle \mathrm{U}$ and $\mathrm{dI} / \mathrm{dU}$ are monotone increasing functions and $|-I / U|$ is a monotone decreasing function. When $|-I / U|>|\mathrm{d} I / d U|$,Working point is on the left of the MPP; $|-I / U|<|\mathrm{d} I / d U|$ on the right; $|-I / U|=|\mathrm{d} I / d U|$ refers to the MPP. When $\mathrm{dI} / \mathrm{dU}$ is replaced by discrete $\triangle \mathrm{I} / \triangle \mathrm{U},|\Delta I / \Delta U|>|\mathrm{d} I / d U|$ refers to the left of the MPP; $|\Delta I / \Delta U|<|\mathrm{d} I / d U|$ on the right; $|\Delta I / \Delta U|=|\mathrm{d} I / d U|$ refers to the MPP. In Fig.5, when tracking from $\left(\mathrm{U}_{1}, \mathrm{P}_{1}\right)$ to $\left(\mathrm{U}_{2}, \mathrm{P}_{2}\right)$, the criterion equation is $|\Delta I / \Delta U|<|\mathrm{d} I / d U|$; when tracking from $\left(\mathrm{U}_{3}, \mathrm{P}_{3}\right)$ to $\left(\mathrm{U}_{4}, \mathrm{P}_{4}\right)$, the criterion equation is $|\Delta I / \Delta U|>|\mathrm{d} I / d U|$.Suppose the system works at point $\left(U_{2}, P_{2}\right)$, thus $|\Delta U|>\left|U_{m}-U_{2}\right|$, the next work point will be $\left(\mathrm{U}_{3}, \mathrm{P}_{3}\right) .\left(\mathrm{U}_{3}, \mathrm{P}_{3}\right)$ may be just $\left(U_{m}, P_{m}\right)$ or on the right of MPP. Analyses are done in the two sides .

(a) $\left(U_{3}, P_{3}\right)=\left(U_{m}, P_{m}\right)$

As can be seen from the Fig.6, $\left(\mathrm{U}_{3}, \mathrm{P}_{3}\right)$ is just at MPP, thus $\left|-I_{3} / U_{3}\right|=\left|d I_{3} / d U_{3}\right|$.At the moment, suppose the system tracks right, we can get, $|\Delta I / \Delta U|<\left|d I_{3} / d U_{3}\right|=\left|-I_{3} / U_{3}\right|$.Then the system can infer

work point is on the left of the MPP and will continue to track right by $\Delta U$, next work point will be $\left(\mathrm{U}_{4}, \mathrm{P}_{4}\right)$. According to the tangent and lagrange theorem, $|\Delta I / \Delta U|$ at (u4, p4) shall be derivative value at a point between $\left(\mathrm{U}_{4}, \mathrm{P}_{4}\right)$ and $\left(\mathrm{U}_{3}, \mathrm{P}_{3}\right),|\mathrm{d} I / d U|$ is increasing and $|-I / U|$ is decreasing, then the system can infer work point is on the right of the MPP and track left to $\left(\mathrm{U}_{3}, \mathrm{P}_{3}\right)$ by $\Delta U$.In the same way, at (u3,p3), $|\Delta I / \Delta U|>\left|d I_{3} / d U_{3}\right|=\left|-I_{3} / U_{3}\right|$, the next point will be( $\left.\mathrm{U}_{2}, \mathrm{P}_{2}\right)$. In this way, the system will oscillate between $U_{2}-U_{3}\left(U_{m}\right)-U_{4}$.

Energy loss caused by Oscillations can be calculated from the equation:

$\mathrm{P}_{\text {loss }}=\mathrm{P}_{\mathrm{m}}-\mathrm{P}_{2}+\mathrm{P}_{\mathrm{m}}-\mathrm{P}_{4}=2 \mathrm{P}_{\mathrm{m}}-\mathrm{P}_{2}-\mathrm{P}_{4}$

(b) $\left(U_{3}, P_{3}\right)$ is on the right of MPP

As can be seen from the Fig.5, when $\left(U_{3}, P_{3}\right)$ is on the right of MPP, since MPP is between $\left(\mathrm{U}_{2}, \mathrm{P}_{2}\right)$ and $\left(U_{3}, P_{3}\right)$, there are three kinds of size relationship between $|\Delta I / \Delta U|$ and $\left|-I_{3} / U_{3}\right|$.

1) When $|\Delta I / \Delta U|>\left|-I_{3} / U_{3}\right|$, the system can infer work point is on the right of the MPP and track left to (U2,P2) by $\Delta U$.In this case, there are three kinds of size relationship between $|\Delta I / \Delta U|$ and $\left|-I_{2} / U_{2}\right|$.

i) When $|\Delta I / \Delta U|>\left|-I_{2} / U_{2}\right|$, according to the previous reasoning, we can analyze and conclude the system will oscillate between $U_{1}-U_{2}-U_{3}$. Energy loss caused by Oscillations can be calculated from the equation:

$\mathrm{P}_{\text {loss }}=\mathrm{P}_{\mathrm{m}}-\mathrm{P}_{1}+\mathrm{P}_{\mathrm{m}}-\mathrm{P}_{2}+\mathrm{P}_{\mathrm{m}}-\mathrm{P}_{3}=3 \mathrm{P}_{\mathrm{m}}-\mathrm{P}_{1}-\mathrm{P}_{2}-\mathrm{P}_{3}$ 
ii) When $|\Delta I / \Delta U|=\left|-I_{2} / U_{2}\right|$, the system would infer work point is just at $\left(\mathrm{U}_{2}, \mathrm{P}_{2}\right)$, but it is not the genuine MPP .The energy loss is:

$\mathrm{P}_{\text {loss }}=\mathrm{P}_{\mathrm{m}}-\mathrm{P}_{2}$

iii) When $|\Delta I / \Delta U|<\left|-I_{2} / U_{2}\right|$, the system would infer work point is on the left of the MPP and track left to $\left(U_{3}, P_{3}\right)$ by $\Delta U$, at $\left(U_{3}, P_{3}\right),|\Delta I / \Delta U|>\left|-I_{3} / U_{3}\right|$, thus next point will be back to $\left(\mathrm{U}_{2}, \mathrm{P}_{2}\right)$. In this way, the system will oscillate between $U_{2}-U_{3}$. The energy loss is:

$\mathrm{P}_{\text {loss }}=\mathrm{P}_{\mathrm{m}}-\mathrm{P}_{2}+\mathrm{P}_{\mathrm{m}}-\mathrm{P}_{3}=2 \mathrm{P}_{\mathrm{m}}-\mathrm{P}_{2}-\mathrm{P}_{3}$

2) When $|\Delta I / \Delta U|=\left|-I_{3} / U_{3}\right|$, the system would infer work point is just at $\left(\mathrm{U}_{3}, \mathrm{P}_{3}\right)$, but it is not the genuine MPP .The energy loss is: $\mathrm{P}_{\text {loss }}=\mathrm{P}_{\mathrm{m}}-\mathrm{P}_{3}$
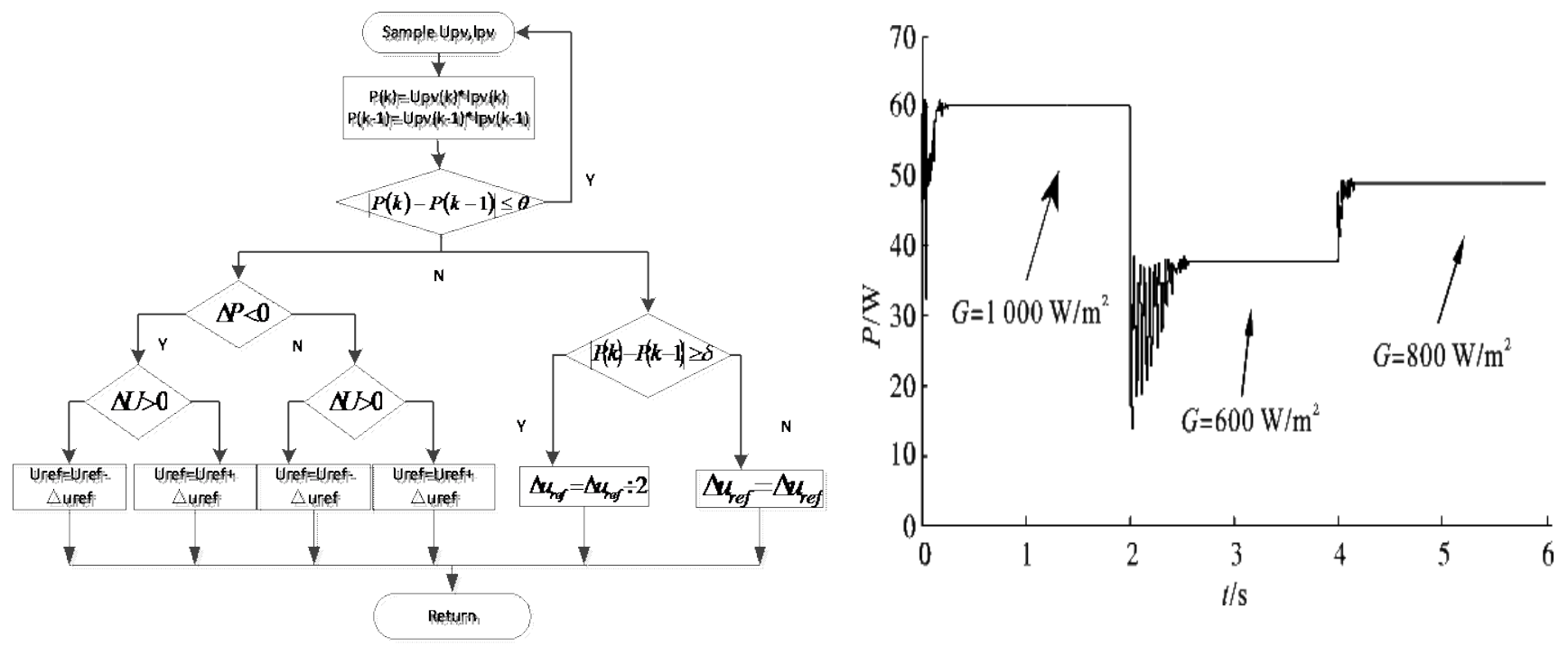

Fig.7.The flow chart of improved method

Fig.8. System output power when light intensity varies

3) When $|\Delta I / \Delta U|<\left|-I_{3} / U_{3}\right|$, the system can infer work point is on the left of the MPP(actually on the right $)$, and track right to $\left(\mathrm{U}_{4}, \mathrm{P}_{4}\right)$ by $\Delta U$. According to the previous reasoning, we can analyze and conclude the system will oscillate between $U_{2}-U_{3}-U_{4}$. The energy loss is:

(17)

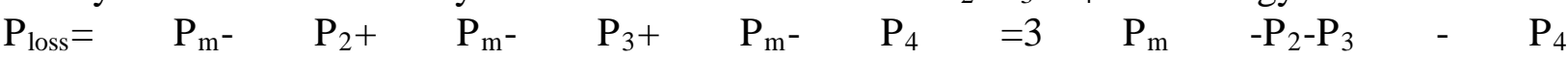

\section{Improved P\&O method.}

Improved method is presented in this paper, based on fixed step P\&O method, the step size is determined by the size of $\Delta P$. The flow chart is showed in Fig.7.

When $\mid P(k)-P(k-1) \leq \theta, \theta$ is the minimum of $\Delta P$, the system can infer work point is just near the MPP and stop perturbing.

When $|P(k)-P(k-1)| \geq \delta, \delta$ is the maximum of $\Delta P$, in this case, we can infer it is the rapid change in light intensity or temperature that lead to that. During this period, the system would switch between different U-I curves. In transient process, misjudgment may occur, therefore, step is halved to ensure the tracking accurate.

When $|P(k)-P(k-1)|<\delta$, the system has run into a new U-I curve,and restore the original step size.

\section{Experimental analysis.}

By MATLAB/Simulink, improved method is validated and simulation is showed in Fig.8. Initially, $T=25^{\circ} \mathrm{C}$ and light intensity is $1000 \mathrm{~W} / \mathrm{m}^{\wedge} 2$. When time is $2 \mathrm{~s}$, light intensity changes to $600 \mathrm{~W} / \mathrm{m}^{\wedge} 2$, then power drops; When time is $4 \mathrm{~s}$, light intensity changes to $800 \mathrm{~W} / \mathrm{m}^{\wedge} 2$, then power rises.Simulation and experimental results show that the proposed method is effective. 


\section{Summary}

This paper analyzes detailedly oscillations ,misjudgment and energy losses in the process of tracking MPP in several MPPT methods, including the fractional Open-Circuit Voltage method, P\&O method and INC method,which is very helpful to improve the efficiency of MPPT and the system. Meanwhile, an improved P\&O method is proposed, simulation and experiments were used to verify the feasibility and functionality of this method in solving oscillation and misjudgment problems.

\section{References}

[1] SONG Liang, WANG XiaoDong, LIU Wen, etc., Research of perturbation and observation method for MPPT of PV Arrays, SEMICONDUCTOR OPTOELECTRONICS, VOL.33 NO.4, Aug.2012.

[2] LAI Dong-sheng,YANG Ping, Variable Step-size Incremental Conductance Used in Maximum Power Point Tracking Control of PV Power System,Power Electronics, Vol.46,No.3 ,March 2012. [3]Yangjing Ou,Chenghua Wang,Feng Hong. A Variable Step Maximum Power Point Tracking

Method Using Taylor Mean Value Theorem[C].Power and Energy Engineering Conference (APPEEC), 2010 Asia-Pacific,Chengdu,2010:1-4.

[4] Liu Bangyin, Duan Shanxu, Liu Fei, Xu Pengwei. Photovoltaic Array Maximum Power Point Tracking Based on Improved Perturbation and Observation Method. TRANSACTIONS OF CHINA ELECTROTECHNICAL SOCIETY, Vol.24 No. 6,Jun. 2009. 